\title{
The effect of radiation on the $\mathrm{OH}^{-}$infrared absorption of quartz crystals
}

\author{
W. A. Sibley, J. J. Martin, M. C. Wintersgill, a) and J. D. Brown \\ Department of Physics, Oklahoma State University, Stillwater, Oklahoma 74074
}

(Received 23 February 1979; accepted for publication 4 April 1979)

\begin{abstract}
The effect of 1.6-MeV-electron irradiation on the infrared properties of high-purity quartz crystals has been studied. The infrared bands assciated with $\mathrm{OH}^{-}$impurities in $\mathrm{SiO}_{2}$ crystals are strongly temperature dependent and must be studied at $77 \mathrm{~K}$ or below. Prolonged electron irradiation at low temperature suppresses all of the $\mathrm{OH}^{-}$bands, but these bands recover when the crystals are annealed to approximately $740 \mathrm{~K}$. If as-grown crystals are irradiated at $300 \mathrm{~K}$, the intensity of the $\mathrm{OH}^{-}$bands decreases and two new bands appear at 3367 and $3306 \mathrm{~cm}^{-1}$. The relative absorption intensity of these two bands depends on radiation temperature and dose.
\end{abstract}

PACS numbers: 78.50.Ec, 78.30.Gt, 61.70.Ey, 61.80.Fe

\section{INTRODUCTION}

High-precision quartz oscillator clocks and filters are widely used in satellite communication and guidance systems. Since the stability of the precision oscillators used in these systems becomes of greater importance as usage increases, a continual effort must be made to develop oscillators that are stable for long periods. ${ }^{1}$ Considerable work has been done in the past on the effect of radiation on $\mathrm{SiO}_{2}$ crystals. ${ }^{2-10}$ However, because of the difficulty of obtaining crystals with homogeneous impurity concentrations or even samples with known impurity content, an understanding of how radiation damage affects the oscillation frequency has not yet been obtained. It is clear from previous research that impurities do play an important role. Changes in impurity states could most certainly affect the frequency stability of oscillators. Since radiation and stress can affect impurity valence states and mobilities, it is not surprising that both can cause instability in oscillation frequency.

When an ionic or covalent material is exposed to radiation, two types of response can occur ${ }^{11}$ : (i) ionizing radiation can cause changes in valence states which may result in mobility of impurities; (ii) incident particles can displace ions if energy transfer from the bombarding particle is sufficiently great. High-energy electrons or protons are most effective for ionic displacements, whereas ionizing radiation creates electron-hole pairs which give rise primarily to valence changes. The displacement cross section for $1-2-\mathrm{MeV}$ electrons impinging upon ions is sufficiently small that, except at very large doses, few ionic displacement type defects are present. On the other hand, if hydrogen or alkali interstitials have the appropriate state, it is possible that, at sufficiently high temperatures, they can be mobile. Thus, ionizing radiation can trigger motion of these impurities along the open channels of crystalline $\mathrm{SiO}_{2}$. This motion will be temperature dependent.

In our work, optical-absorption studies of unirradiated and irradiated quartz have been made using ultraviolet, visible, and infrared light. A number of electron paramagnetic resonance (EPR) studies have also been made by our coworkers, Markes and Halliburton. ${ }^{12}$ The latter spectra are

\footnotetext{
a)Present address: Department of Physics, U.S. Naval Academy, Annapolis, Maryland 21402.
}

complex but do yield valuable information on the redistribution of electrons and holes by radiation. This work will concentrate on infrared absorption data. However, attempts will be made to correlate the infrared measurements with both EPR and visible optical-absorption results where possible. The purpose of this paper is to present data corroborating some of the existing information available on $\mathrm{OH}$ - infrared transitions in $\mathrm{SiO}_{2}$ crystals and to give additional results on the mobilities and locations of impurities in $\mathrm{SiO}_{2}$.

\section{EXPERIMENTAL PROCEDURE}

Single-crystal ingots of both Electronic and Premium $Q$ material were purchased from Sawyer Research Products, Inc. Specimens were cut such that the $c$ axis was parallel to the incident beam of the monitoring light. In this case the electric vector of the incident light $E$ was always perpendicular to the $c$ axis $(E \perp c)$. After the crystals were cut and polished, infrared absorption was measured on a Beckman 4240 spectrophotometer. The visible and ultraviolet spectral ranges were measured using a Cary 14 spectrophotometer. A cryostat equipped with $\mathrm{CaF}_{2}$ windows and capable of reaching $7 \mathrm{~K}$ with temperature controllable to $\pm 2 \mathrm{~K}$ was utilized.

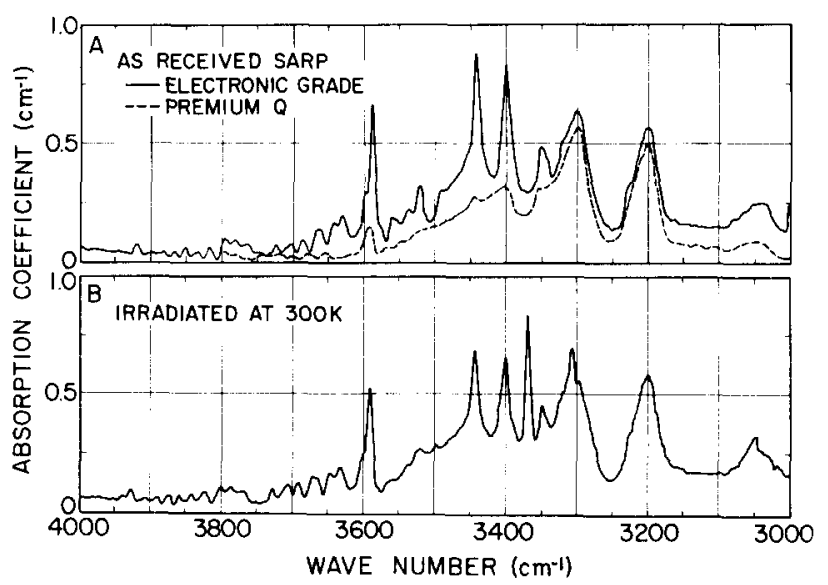

FIG. I. In A, the upper solid curve shows the infrared absorption taken at $77 \mathrm{~K}$ for a SARP Electronic grade sample in the as-received condition. The dashed curve shows the results for a SARP Premium $Q$ sample. In $B$, the infrared absorption in the Electronic grade sample after a $300 \mathrm{~K}$ irradiation to a dose of $2000 \mathrm{~J} / \mathrm{cm}^{3}$ is shown. This irradiation has produced the bands at $3306-$ and $3367 \mathrm{~cm}^{-1}$. 
TABLE I. Prominent OH bands as measured at $77 \mathrm{~K}$ for Electronic grade quartz.

\begin{tabular}{llll}
\hline \hline $\begin{array}{l}\text { Wave number } \\
\left(\mathrm{cm}{ }^{1}\right)\end{array}$ & $\begin{array}{l}\alpha_{m} \\
\left(\mathrm{~cm}{ }^{1}\right)\end{array}$ & $\begin{array}{l}H \\
\left(\mathrm{~cm}{ }^{1}\right)\end{array}$ & Comments \\
\hline 3581 & $0.61(0.06)^{\mathrm{a}}$ & 6 & Unirradiated \\
3437 & $0.71(0.04)$ & 12 & Unirradiated \\
3400 & 0.75 & 12 & Unirradiated \\
3348 & 0.25 & 16 & Unirradiated \\
3367 & 0.61 & 7 & Irradiated at 300 K \\
3306 & 0.23 & 7 & Irradiated at 300 K \\
\hline \hline
\end{tabular}

${ }^{a}$ The values in parentheses are for a Premium $Q$ sample.

Irradiations were made with a Van de Graaff electron accelerator. Most often the irradiations were done with 1.6$\mathrm{Mev}$ electrons and a current of approximately $0.2 \mu \mathrm{A} / \mathrm{cm}^{2}$ on the samples. Since the penetration depth of these electrons is about $2 \mathrm{~mm}$ in $\mathrm{SiO}_{2}$, samples with greater thickness were irradiated on both sides. The radiation port for the cryostat consisted of a 5-mil aluminum window.

\section{RESULTS}

The differences in the infrared optical properties of Sawyer Electronic grade and Sawyer Premium $Q$ grade quartz are illustrated in Fig. 1. The data are for the $E \perp c$. From Fig. 1 it can be seen that the spectrum typical of Premium $Q$ samples exhibits primarily rather broad intrinsic quartz lattice mode overtone absorption at 3200,3300 , and $3400 \mathrm{~cm}^{-1}$. Other extrinsic bands are also present around $3400 \mathrm{~cm}^{-1}$ since there are changes in this region with radiation dose. The $\mathrm{OH}{ }^{-}$stretching modes are evidenced by the sharp peaks and are obviously much less intense in the Premium $Q$ specimens (dashed line) than in the Electronic Grade material (solid line). Table I lists the wavelengths, widths at half-maximum $H$, and the maximum absorption coefficient for the most prominent bands in the two materials. In the past both Kats ${ }^{3}$ and Bates and Perkins ${ }^{13}$ have found relationships which connect the concentration of hydrogen ions per $\mathrm{cm}^{3} N_{\mathrm{H}}$ with the maximum absorption coefficient, $\alpha_{m}\left(\mathrm{~cm}^{-1}\right)$, and the half-width, $H\left(\mathrm{~cm}^{-1}\right)$, of the various $\mathrm{OH}$ bands. They determined that $N_{\mathrm{H}}=1.8$ $\times 10^{16} \mathrm{Ho}_{m} \mathrm{~cm}^{-3}$. The data in Table I suggest that Premium $Q$ crystals contain less than $3 \times 10^{16} \mathrm{~cm}^{-3}$ hydrogens participating as $\mathrm{OH}^{-}$, whereas the Electronic grade material contains approximately $4 \times 10^{17}$ hydrogens $\mathrm{cm}^{-3}$ in this state. The measurements illustrated in Fig. 1 were made at $77 \mathrm{~K}$. As has been shown by Lipson et al., ${ }^{14}$ the $\mathrm{OH}$ bands are very temperature sensitive. In fact, for our samples, measurements at $300 \mathrm{~K}$ show only intrinsic $\mathrm{SiO}_{2}$ overtone bands. There is a considerable change in the intensity of the $\mathrm{OH}$ bands over the temperature range 7-77 K. It is imperative that infrared measurements be made at $77 \mathrm{~K}$ or lower if defect bands are to be monitored.

When samples are irradiated at either 10 or $77 \mathrm{~K}$ with low doses of electrons (an absorbed energy of about 500 $\mathrm{J} / \mathrm{cm}^{3}$ ), few changes are observed. In the Electronic grade crystals the $3581-\mathrm{cm}^{-1}$ band decreases and the small $3367-$ $\mathrm{cm}^{-1}$ band disappears. No other noticeable effects are observed. For larger doses all the bands decrease markedly and

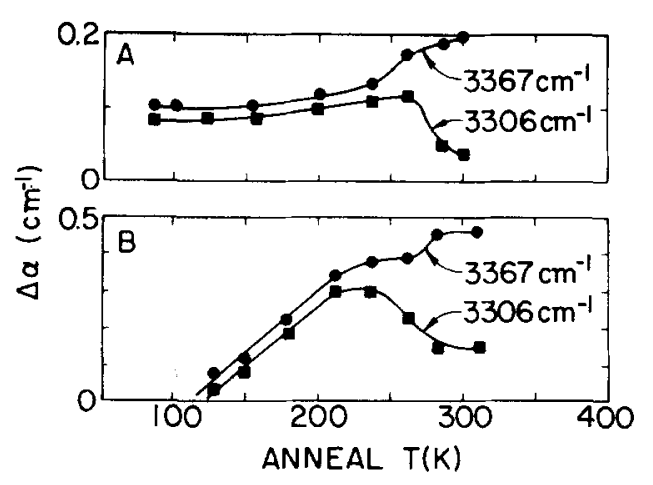

FIG. 2. The absorption coefficients of the 3306 and $3367 \mathrm{~cm}^{-1}$ bands are shown as functions of isochronal anneal temperature following a $77 \mathrm{~K}$ irradiation. Curve $A$ is for a sample irradiated to a dose of $500 \mathrm{~J} / \mathrm{cm}^{3}$, and curve $B$ is for a sample irradiated to a dose of $2000 \mathrm{~J} / \mathrm{cm}^{3}$.

for doses greater than $2000 \mathrm{~J} / \mathrm{cm}^{3}\left(\sim 10^{8} \mathrm{rads}\right)$ all bands disappear. The bands only partially recover their original strength upon annealing to room temperature.

If instead the material is irradiated at $300 \mathrm{~K}$ to a dose of about $2000 \mathrm{~J} / \mathrm{cm}^{3}$ and then measured at $77 \mathrm{~K}$, it is found that the original $\mathrm{OH}$ bands have decreased and two intense bands appear at 3367 and $3306 \mathrm{~cm}^{-1}$ with the total area under the $\mathrm{OH}$ bands remaining constant. The lower curve in Fig. 1 shows this behavior for a SARP Electronic grade sample. It should be noted that the intensity of the $3306-\mathrm{cm}^{-1}$ band is considerably less than that of the $3367-\mathrm{cm}^{-1}$ band for a $300 \mathrm{~K}$ irradiation. However, the intensity ratio of these two bands depends on the radiation temperature and dose.

If a sample which has been irradiated at $300 \mathrm{~K}$ to produce the two bands at 3367 and $3306 \mathrm{~cm}^{-1}$ is given a brief low-dose irradiation $\left(500 \mathrm{~J} / \mathrm{cm}^{3}\right)$ at either 77 or $10 \mathrm{~K}$, the $3367-\mathrm{cm}^{-1}$ band decreases and the 3306- $\mathrm{cm}^{-1}$ band increases as shown in curve A of Fig. 2. If the sample is then isochronally annealed, the two bands retain their relative strengths until $230 \mathrm{~K}$ is reached. Above $230 \mathrm{~K}$ they quickly recover the original intensities produced by the $300 \mathrm{~K}$ irradiation. The recovery is essentially complete by $270 \mathrm{~K}$. The sharpness with which this recovery takes place suggests that the process is not a migration event governed by Boltzmann statistics. A higher-dose $\left(2000 \mathrm{~J} / \mathrm{cm}^{3}\right)$ irradiation at $77 \mathrm{~K}$ suppresses both bands. Upon annealing, both bands recover with nearly equal strength at $110 \mathrm{~K}$, as shown in curve $B$ of Fig. 2. The recovery is essentially complete by $200 \mathrm{~K}$ and the rearrangement process described above again takes place between 230 and $270 \mathrm{~K}$.

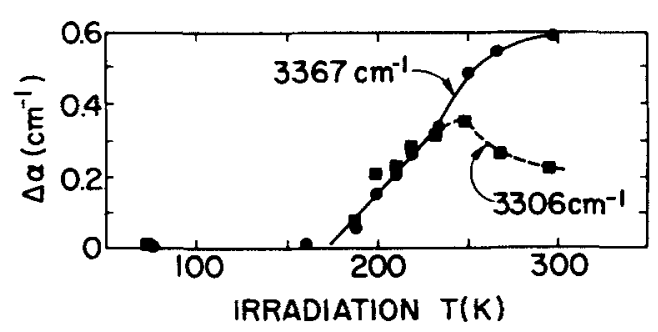

FIG. 3. The production of the 3306 and $3367-\mathrm{cm}^{-1}$ bands as a function of sample temperature during irradiation is shown. 


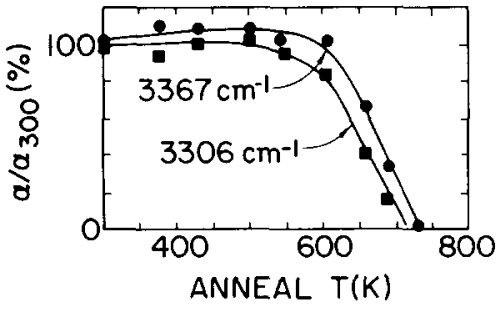

FIG. 4. The high-temperature annealing behavior of the 3306- and 3367$\mathrm{cm}{ }^{1}$ bands is shown. The initial absorption coefficients were 0.21 and $0.58 \mathrm{~cm}$ ', respectively. The sample was held at each temperature for 10 min and then quenched in liquid nitrogen.

The production of the 3306- and 3367-cm ${ }^{-1}$ bands under electron irradiation is strongly temperature dependent. Figure 3 shows the production of these two bands versus the irradiation temperature. The bands are not formed when the irradiation takes place at temperatures below $180 \mathrm{~K}$. Above $180 \mathrm{~K}$, the bands grow in nearly equal intensities up to about $230 \mathrm{~K}$. Above this temperature, as mentioned above, the distribution of the defect centers quickly changes to the ratio established by a $300 \mathrm{~K}$ irradiation.

The high-temperature annealing of the irradiation-induced 3306- and 3367- $\mathrm{cm}^{-1}$ bands is portrayed in Fig. 4. Both bands are stable to $600 \mathrm{~K}$ and disappear by $740 \mathrm{~K}$. In this treatment the crystals were held for $10 \mathrm{~min}$ at room temperature and then quenched in liquid nitrogen. After the annealing series was complete, the samples were reirradiated at room temperature. In this case the $3306-$ and $3367-\mathrm{cm}^{-1}$ bands both reappeared in the same proportion as before annealing. As mentioned above, when samples are irradiated at $300 \mathrm{~K}$ to relatively higher doses $\left(2 \mathrm{~K} \mathrm{~J} / \mathrm{cm}^{3}\right)$, the infrared bands at 3581,3439 , and $3400 \mathrm{~cm}^{-1}$ decrease by about a factor of 2. Larger doses can eliminate them completely. These bands regain their initial intensity when the irradiated specimens are annealed at $740 \mathrm{~K}$.

\section{DISCUSSIONS}

In the past, excellent research on the infrared absorption of quartz has been done by Kats, ${ }^{3}$ Brown and Kahan, ${ }^{9}$ and Lipson et $a l .{ }^{14} \mathrm{Kats}$ 's work is encyclopedic. He studied a large number of quartz samples, both natural and synthetic, and attempted to correlate their infrared absorption at low temperature with impurities detected by chemical analyses. From this work Kats tentatively identified certain absorption peaks with the presence of alkali and $\mathrm{Al}^{3+}$ ions. Many of these same bands were observed by Brown and $\mathrm{Kahan}^{9}$ in purer samples. Recently Lipson et al. ${ }^{14}$ have found that four bands, 3348, 3396, 3437, and $3581 \mathrm{~cm}^{-1}$, are present in both SARP Electronic grade and Premium $Q$ specimens. Kats earlier identified bands at $3400 \mathrm{~cm}^{-1}$ as due to $\mathrm{OH}$ perturbed by $\mathrm{Li}^{+}$and at $3581 \mathrm{~cm}^{-1}$ as due to $\mathrm{OH}^{-}$in the vicinity of $\mathbf{K}^{+}$. The relative intensities of the bands in Electronic grade and Premium $Q$ samples are given in Table $\mathrm{I}$. Some caution must be used in evaluating both the absorption and the impurity analyses since Lipson et al. ${ }^{14}$ have illustrated that impurities can be inhomogeneously distributed in these crystals. Despite the fact that Kats ${ }^{7}$ was tentatively able to identify many of the infrared-absorption peaks with the presence of alkali impurity ions such as $\mathrm{Na}^{+}$and $\mathrm{Li}{ }^{+}$, it has not been possible in the purer materials to find evidence of his series of bands. In fact, at this stage it is not possible to identify conclusively any of the bands observed in either the Premium $Q$ or the Electronic grade samples.

On the other hand, the observation that the $\mathrm{OH}$ absorption bands decrease with radiation dose even at $15 \mathrm{~K}$ indicates that some form of hydrogen is mobile in quartz even at these low temperatures. If this effect were due to only a local mobility of the hydrogen or proton, then it might be expected that with warming of the sample the infrared spectrum would return to its preirradiated appearance. Since this does not happen until very high temperatures, there must be longrange mobility.

This result is consistent with the EPR studies of Markes and Halliburton ${ }^{12}$ on similar samples. They have observed atomic hydrogen, $\mathrm{H}^{0}$, and several other $\mathrm{H}$-related centers following a low-temperature irradiation. Their results show that the hydrogen atoms anneal out near $120 \mathrm{~K}$ but that the other H-related EPR centers do not decay until much higher temperatures are reached.

Even though hydrogen may be mobile in a radiation field at low temperatures, alkalis are not. However, there is indirect evidence that alkalis are mobile in a radiation field at temperatures above $180 \mathrm{~K}$. The absorption bands at 3306 and $3367 \mathrm{~cm}^{-1}$ appear with irradiation at temperatures above $180 \mathrm{~K}$ as shown in Fig. 3. Kats ${ }^{3}$ postulated that these two bands were due to $\mathrm{OH}-$ ions in the vicinity of $\mathrm{Al}^{3+}$ ions with no alkali ions nearby. If this model is correct, then the appearance of the 3306 and $3367-\mathrm{cm}^{-1}$ bands would result from the following process. Alkali ions are near $\mathrm{Al}^{3+}$ ions where they act as charge compensators. In a radiation field the alkalis migrate away and are replaced by $\mathrm{H}^{+}$ions or holes trapped in the nonbonding orbitals of neighboring oxygen ions.

Markes and Halliburton ${ }^{12}$ have found an enhanced production of the $\left[\mathrm{Al}_{e^{+}}\right]^{0}$ center by low-temperature irradiation if the sample was first irradiated above $200 \mathrm{~K}$. This result is consistent with the model of the high-temperature radiationinduced motion of the alkali away from the $\mathrm{Al}^{3}+$ impurity which then traps an $\mathrm{H}^{+}$ion. During the subsequent lowtemperature irradiation the $\mathrm{H}^{+}$is moved away from the $\mathrm{Al}^{3+}$ and a hole is trapped there for charge compensation. It is already well known that when crystals are placed in an electric field of $10^{3} \mathrm{~V} / \mathrm{cm}$ at $775 \mathrm{~K}$ these same 3306- and $3367-\mathrm{cm}^{-1}$ bands appear. ${ }^{3}$ It is believed that alkali ions are swept out of the crystals in this process. Thus, it appears that electron irradiation at temperatures above $180 \mathrm{~K}$ generated alkali atom motion and the resulting effect is much like that produced by the sweeping process.

However, the 3306- and $3367-\mathrm{cm}^{-1}$ bands do not grow together with radiation as has been suggested in the past. They are probably due to $\mathrm{OH}{ }^{-}$ions in two different but closely related site symmetries. The fact that the transfer from one site to another occurs so sharply around $240 \mathrm{~K}$ suggests that a phonon-assisted process is involved. In particular, if a bending or rotational mode of vibration of the $\mathrm{SiOH}$ - or $\mathrm{AlOH}$ - -type defects has the appropriate 
phonon frequency to shift hydrogen from one site to the other site, then this type of sharp transformation might be expected.

The high-temperature annealing of irradiated quartz reestablishes the original distribution of hydrogen and alkalis at various sites in the material. This redistribution of hydrogen at high temperatures is not unexpected. Similar behavior is observed in $\mathrm{MgO}$ where changes from brucite $\mathrm{Mg}(\mathrm{OH})_{2}$ precipitates to isolated $\mathrm{MgO}(\mathrm{OH})_{2}$ molecules in the lattice occur due to various heat treatments. ${ }^{15}$

The irradiated quartz samples were also investigated for visible and ultraviolet absorption. Some workers in the past have attributed the smokey quartz coloration to socalled $\left[\mathrm{Al}_{e^{+}}\right]^{0}$ trapped hole centers ${ }^{16}$ mentioned earlier. In our investigation of both Electronic and Premium $Q$ SARP samples no smokey coloration is observed. Nassau and his collaborators ${ }^{17}$ have indicated in the past that there is no connection between the Al-hole centers and visible absorption.

Jones and Embree ${ }^{18}$ recently suggested a correlation between a luminescence band and the presence of oxygen vacancies which were detected by means of ultraviolet absorption. We have not observed any increase in the uv absorption for the radiation doses in our experiments. For the $1.6-\mathrm{MeV}$ electrons and doses of up to $2000 \mathrm{~J} / \mathrm{cm}^{3}$ only very few radiation oxygen vacancies would be produced. It is planned to irradiated to the higher doses needed to produce oxygen vacancies and to look for the associated uv absorption and luminescence.

\section{SUMMARY}

In summary we have found the following:

(1) The $\mathrm{OH}$ - infrared bands in quartz are strongly temperature dependent. Consequently, they must be studied at temperatures of $77 \mathrm{~K}$ or below.
(2) Prolonged low-temperature irradiation suppresses all of the $\mathrm{OH}$ bands. They recover upon annealing to $740 \mathrm{~K}$.

(3) Irradiation at room temperature lowers the original $\mathrm{OH}$ bands and produces a strong band at $3367 \mathrm{~cm}^{-1}$ and a less intense band at $3306 \mathrm{~cm}^{-1}$. A subsequent irradiation at $77 \mathrm{~K}$ switches these two bands to a nearly equal intensity. Upon annealing they recover their original strengths near $240 \mathrm{~K}$.

\section{ACKNOWLEDGMENTS}

This work was supported by the U.S. Air Force under contract RADC/ESM, Hanscom AFB, Mass. 01731, monitored by A.F. Armington.

'C. Audoin and J. Vanier, J. Phys. E 9, 697 (1976).

${ }^{2}$ A. Kats and Y. Haven, Phys. Chem. Glasses 1, 99 (1960).

${ }^{3}$ A. Kats, Philips Res. Rep. 17, 133 (1962)

${ }^{4}$ R.A. Weeks, Phys. Rev. 130, 570 (1963).

'D.M. Dodd and D.B. Fraser, J. Phys. Chem. Solids 26, 673 (1965)

${ }^{6}$ D.B. Fraser, Physical Acoustics, edited by W.P. Mason (Academic, New York, 1968), Vol. 5, Chap. 2.

'J.H. Mackey, J.W. Boss, and D.E. Wood, J. Magn. Reson. 3, 44 (1970). ${ }^{8}$ J.A. Weil, Radiat. Eff. 26, 261 (1975)

${ }^{9}$ R.N. Brown and A. Kahan, J. Phys. Chem. Solids 36, 467 (1975).

${ }^{10}$ G.B. Krefft, Radiat. Eff. 26, 249 (1975)

"E. Sonder and W.A. Sibley, Point Defects in Solids, edited by J.H. Crawford and L.M. Slifkin (Plenum, New York, 1973), Vol. 1, Chap. 4.

${ }^{12}$ M. Markes and L.E. Halliburton (unpublished).

${ }^{13}$ J.B. Bates and R.A. Perkins, Phys. Rev. 1316, 3713 (1977).

${ }^{14}$ H.G. Lipson, F. Euler, and A.F. Armington, Proceedings of the $32 \mathrm{nd}$ Annual Symposium on Frequency Control, U.S. Army Electronics Command, Fort Monmouth, N.J., 1978, pp. 11-23 (unpublished).

'B. Henderson and W.A. Sibley, J. Chem. Phys. 55, 1276 (1976).

${ }^{10}$ R. Schnadt and J. Schneider, Phys. Kondens Mater. 11, 19 (1970).

${ }^{17}$ K. Nassau and B.E. Prescott, Phys. Status Solidi A 29, 259 (1975). Mineral. Mag. 41, 301 (1977); Am. Mineral. 62, 589 (1977); 63, 230 (1978).

${ }^{18}$ C.E. Jones and D. Embree, J. Appl. Phys. 47, 5365 (1976). 